\title{
Third wave of African swine fever infection in Armenia: Virus demonstrates the reduction of pathogenicity
}

\author{
M. A. Sargsyan ${ }^{1}$, H. E. Voskanyan², E. M. Karalova², L. H. Hakobyan² and Z. A. Karalyan²,3
}

1. Department of Epizootiology and Parasitology, Armenian National Agrarian University, Yerevan 0009, Armenia; 2. Laboratory of Cell Biology and Virology, Institute of Molecular Biology of The National Academy of Sciences of the Republic of Armenia (NAS RA), 7 Hasratyan St., Yerevan 0014, Armenia; 3. Department of Biology, Yerevan State Medical University, Yerevan, Armenia.

Corresponding author: Z. A. Karalyan, e-mail: zkaralyan@yahoo.com

Co-authors: MAS: mariam.sargsyan.1960@mail.ru, HEV: aleksvoskanyan@mail.ru, EMK: hatussili@yahoo.com, LHH: lina.hakobyan@gmail.com

Received: 10-09-2017, Accepted: 05-12-2017, Published online: 11-01-2018

doi: 10.14202/vetworld.2018.5-9 How to cite this article: Sargsyan MA, Voskanyan HE, Karalova EM, Hakobyan LH, Karalyan ZA (2018) Third wave of African swine fever infection in Armenia: Virus demonstrates the reduction of pathogenicity, Veterinary World, 11(1): 5-9.

\begin{abstract}
Aim: First cases of clinically uncommon African swine fever (ASF), caused by virus genotype II are described in this article. These cases occurred in Armenia, Tavush region, Dilijan municipality in 2011. The aim of this study was to identify and describe the new pathogenic forms of ASF in Armenia.

Materials and Methods: The isolation and identification of ASF virus (ASFV) were carried out using conventional techniques. Clinical signs of infection were recorded daily. Gross anatomical pathology characteristics were observed during routine postmortem examinations. Blood and serum were obtained by puncture of the jugular vein using a vacutainer system.

Results: The presence of ASFV DNA in the spleens was confirmed by polymerase chain reaction. Sequenced sections of p72 showed phylogenetic identity to genotype 2 . The pathology exhibits unusual manifestations of the main disease. The unusual form of ASF demonstrates characteristics of a subacute form of the disease, with the possibility of conversion to a chronic form. Decreased lethality, low level of hemorrhages, and absence of severe pancytopenia in smears from spleen, lymph nodes, and blood are common features of the new form of ASF. Unlike severe thrombocytopenia in the typical ASF, the unusual form exhibited moderate or minor decrease of this feature. Despite a moderate decrease in hemadsorption titers, the unusual pattern of the disease was characterized by viremia and the presence of the virus in the visceral organs, including the brain.
\end{abstract}

Conclusion: Our data allow assuming that new nosological form of ASF (genotype II) may present as a transitional form of the disease with the possibility of chronization.

Keywords: African swine fever, chronization, new isolate, viremia.

\section{Introduction}

African swine fever (ASF) is the main threat to the porcine industry in the world. Depending on viral and host factors, ASF virus (ASFV) infection of domestic swine can be expressed in several disease forms, ranging between highly lethal (up to 100\%) and subclinical. Manifestations in 2007 ASF affecting domestic pigs and wild boars have been reported in the Caucasus region for the first time. The virus strain involved was related to isolates of genotype II. Almost all cases of ASF caused by genotype II can be described as peracute, acute, and/or subacute forms [1].

Initially, ASF cases in Dilijan district were recorded in 2007, while the first cases of atypical ASF

\footnotetext{
Copyright: Sargsyan, et al. Open Access. This article is distributed under the terms of the Creative Commons Attribution 4.0 International License (http://creativecommons.org/licenses/ by/4.0/), which permits unrestricted use, distribution, and reproduction in any medium, provided you give appropriate credit to the original author(s) and the source, provide a link to the Creative Commons license, and indicate if changes were made. The Creative Commons Public Domain Dedication waiver (http:// creativecommons.org/publicdomain/zero/1.0/) applies to the data made available in this article, unless otherwise stated.
}

in Armenia, in Dilijan district, evolved in 2011 [2]. During the first epidemic wave, a hundreds of pigs were affected and eliminated from different farms. The second epidemic wave in the same region was detected in 2009 with the number of infected pigs exceeding the previous epidemic wave. The third epidemic wave was recorded in the same region in 2011. In the period from late autumn to early winter 2011 along with the typical forms of the disease were detected isolated cases of atypical course of ASF. First cases were reported in Dilijan municipality in Taush province (North-East of Armenia). All cases of atypical ASF were recorded in several farms from November 29 to December 18, 2011 [2]. Atypical ASF was observed in over 70 animals. Postmortem investigations and laboratory studies were conducted in the Institute of Molecular Biology (IMB), Armenia. ASFV sample that has been obtained from infected pigs was referred to as Dilijan 2011 IMB.

It is well known that transmission of ASF virus can occur through direct contact between sick and healthy pigs or by contact with infectious excretions 
and secretions. Indirect transmission can also occur if healthy animals ingest infected meat products or have contact with contaminated fomites [3]. In the context of virus transmission, chronization of disease increases risks of its transmission. First cases of clinically uncommon ASF, caused by virus genotype II, and characterized by chronization of disease, are described in this article. These cases occurred in Armenia, Tavush region, Dilijan district in 2011. Scientific investigations of the new nosological form of ASFV started in 2014 after the conclusion of an agreement with the Armenian National Agrarian University, which owned the primary material. Partial genome sequencing was performed in 2015, and several gene sequences were completed. The aim of this study was to identify and describe the new pathogenic forms of ASF in Armenia.

\section{Materials and Methods}

\section{Ethical approval}

Biological samples collection was approved by the Institutional Review Board/Independent Ethics Committee of the Institute of Molecular Biology of NAS RA (reference number IRB00004079).

\section{Sample collection}

Biological samples were collected on November 30, 2011, and December 15, 2011. The investigated pigs were free from known porcine viral diseases and vaccinated against the classical swine fever. Blood and serum were obtained by puncture of the jugular vein using a vacutainer system. Samples of liver, brain, bone marrow, heart, kidney, spleen, lymph nodes, and lung were taken and held in separate, disposable plastic containers.

Clinical signs of infection were recorded daily. Gross anatomical pathology characteristics were observed during routine postmortem examinations.

\section{Laboratory analysis}

Laboratory analyses were conducted at the Laboratory of Cell Biology and Virology, IMB of National Academy of Sciences of Armenia. All stages of processing and sample preparation for the diagnosis of ASF were performed in a biosafety level 3 laboratory by qualified staff. Blood clots from dead pigs were used to obtain serum samples, and kidney, lung, brain, bone marrow, liver, spleen, and lymph node biopsies were used for tissue samples.

DNA was extracted from $200 \mu$ of heparinized whole blood samples and spleen samples by using a 5 PRIME Archive Pure DNA Cell/Tissue kit. Specific oligonucleotide primers and the fluorogenic probe were designed to target a highly conserved region within the B646L (p72) and B602L (chaperon) open reading frames. For phylogenetic analysis of ASFV, a portion of the highly conserved p72 gene was amplified and sequenced. The amplified products were characterized by nucleotide sequencing and compared to those obtained from published sequences.

\section{Results}

Before third epidemic wave in Armenia, all ASF cases were documented as well-known peracute (rare) and acute and/or subacute (typical) forms [4]. Isolated cases of atypical course of ASF were detected along with typical forms of the disease in the period between late autumn and early winter 2011 in Dilijan. All cases of atypical ASF were recorded only on several from November 29 to December 18, 2011. First, the aged sows were affected than young piglets (up to 3 months old).

Table-1 presents data of laboratory tests of pigs infected by Georgia 2007 and Dilijan 2011 IMB. Studies of clinical manifestations of typical ASF (Georgia 2007) and unusual ASF (Dilijan 2011 IMB) found that unusual ASF developed obviously attenuated course of the disease. It manifested in slowed down formation of petechial hemorrhages, less intense fever, elongation of the disease duration, and development of chronic forms of pathology. The presence of ASFV DNA in the spleens was confirmed by polymerase chain reaction (PCR). We compared the nucleotide sequences obtained from the p72-based PCRs with those of previously described representative isolates. The Dilijan 2011 IMB ASFV clustered, as expected, within p 72 genotype II. It showed $100 \%$ nucleotide identity with all compared ASFV circulating in the Caucasus regions since 2007.

Postmortem examination at autopsy of the pigs infected by Georgia 2007 and Dilijan 2011. IMB isolates revealed that infection with new isolate leads to a reduction in both the number and size of hemorrhages in all visceral organs. However, swelling of the spleen and liver still persisted. Most of the lymph nodes were not affected. Specifically, unusual ASF was characterized by insignificant lymphopenia in the blood, bone marrow, and spleen. In lymph nodes, lymphopenia was absent. In all studied tissues, leukocyte population demonstrated a slight left shift. It is also necessary to state about marked (approximately 1.5-2.0 log) reduction of ASFV hemadsorption titers (compared to Georgia 2007 isolate) in porcine sera, despite the verified finding of virus in all the viscera of pigs.

Figure-1 shows comparative gross anatomical pathology in pigs infected by Georgia 2007 and Dilijan 2011 IMB. The spleen was enlarged and showed multiple hemorrhages in infection with Georgia 2007 (Figure-1a, arrowed) and Dilijan 2011 IMB isolate caused usually the only enlargement of the spleen (Figure-1b). Massive infarctions of the heart and lungs of animals infected by Georgia 2007 isolate were found (Figure-1c), and infection with Dilijan 2011 IMB manifested minor infractions in the lungs (Figure-1d). Hemorrhages in the liver were very common in infection with Georgia 2007 isolate and sometimes could develop generalized forms with confluent hemorrhage (Figure-1e). This pathology was not observed in infection produced by Dilijan 
Table-1: Main clinical characteristics of typical and unusual ASF.

\begin{tabular}{|c|c|c|}
\hline Main indices & Typical ASF & Unusual ASF \\
\hline $\begin{array}{l}\text { Petechial hemorrhages of the } \\
\text { skin }\end{array}$ & $\begin{array}{l}\text { Extensive petechial hemorrhages (first } \\
\text { arouse } 2-3 \mathrm{dpi} \text { ) of the skin, especially } \\
\text { over the ears, flanks, back, ventral areas } \\
\text { of the thorax, and abdomen. On the skin, } \\
\text { single hemorrhage shows a tendency to } \\
\text { fuse (indicated on } 3-5 \mathrm{dpi} \text { ). Hemorrhages } \\
\text { color varies from dark pink to dark violet }\end{array}$ & $\begin{array}{l}\text { Extensive petechial hemorrhages (first } \\
\text { arouse } 7-8 \text { ) of the skin, especially over the } \\
\text { ears, back, and ventral areas (indicated } \\
\text { on } 9-11 \mathrm{dpi} \text { ). In about } 60 \% \text {, petechial } \\
\text { hemorrhages were absent Hemorrhages } \\
\text { color usually is pink and sometimes violet }\end{array}$ \\
\hline Body temperature & $\begin{array}{l}\text { Usually ranged between } 39^{\circ} \mathrm{C} \text { and } 41.1^{\circ} \mathrm{C} \text {, } \\
\text { in some animal increased up to } 40-42^{\circ} \mathrm{C}\end{array}$ & Moderate fever, irregular, or absent \\
\hline Behavior & Anorexia and depression & $\begin{array}{l}\text { Getting together, anorexia and depression } \\
\text { on the late stage of disease }\end{array}$ \\
\hline Nasal discharge & Serous, mucoid, and/or purulent & Not purulent \\
\hline Digestive tract symptoms & $\begin{array}{l}\text { Vomiting (in rare cases), bloody } \\
\text { diarrhea (in about } 30-50 \% \text { ) }\end{array}$ & Absent \\
\hline First symptom & Increased temperature, loss of appetite & $\begin{array}{l}\text { Moderately increased temperature, lack of } \\
\text { appetite }\end{array}$ \\
\hline Other symptoms & Shallow and rapid respiration, ataxia & Ataxia \\
\hline Disease duration & 5-7 days & 11-12 days \\
\hline Death & $\begin{array}{l}\text { Usually at } 7^{\text {th }} \text { day post-infection; in about } \\
20-30 \% \text { cases at } 5 \mathrm{dpi}\end{array}$ & $\begin{array}{l}\text { Usually after } 7-10 \text { days after arising } \\
\text { of the first symptoms (about } 2 \text { weeks } \\
\text { post-infection) }\end{array}$ \\
\hline Lethality & $100 \%$ & About $90-95 \%$. Chronization in rare cases \\
\hline Myelogram & $\begin{array}{l}\text { Severe lymphopenia. Decrease in the } \\
\text { number of mature lymphocytes the } \\
\text { number of immature immune cells, } \\
\text { particularly myelocytes increased }\end{array}$ & $\begin{array}{l}\text { Moderate lymphopenia with slight left shift. } \\
\text { Light leukocytosis with slight left shift }\end{array}$ \\
\hline Splenogram & $\begin{array}{l}\text { Severe lymphopenia. Decrease in the } \\
\text { number of mature lymphocytes, } \\
\text { the number of immature immune cells, } \\
\text { particularly myelocytes increased }\end{array}$ & $\begin{array}{l}\text { Moderate lymphopenia, increased number } \\
\text { of immature immune cells }\end{array}$ \\
\hline Lymphogram & $\begin{array}{l}\text { Severe lymphopenia. Decrease in the } \\
\text { number of mature lymphocytes the } \\
\text { number of immature immune cells, } \\
\text { particularly myelocytes increased. } \\
\text { Erythroblastosis }\end{array}$ & $\begin{array}{l}\text { Absence of lymphopenia, increased number } \\
\text { of immature immune cells. Erythroblastosis }\end{array}$ \\
\hline Blood & $\begin{array}{l}\text { Lymphopenia. Decrease in the number } \\
\text { of mature lymphocytes the number of } \\
\text { immature immune cells, particularly } \\
\text { myelocytes increased. Severe } \\
\text { thrombocytopenia. Erythroblastosis }\end{array}$ & $\begin{array}{l}\text { Moderate leukocytosis with slight left shift. } \\
\text { Moderate or minor thrombocytopenia. } \\
\text { Erythroblastosis }\end{array}$ \\
\hline PCR confirmed presence & All organs including head and brain & All organs including head and brain \\
\hline ASFV titers in porcine sera & Positive, 4.0-5.5 HAD 50/mL & Positive, $2.5-3.0 \mathrm{HAD} 50 / \mathrm{mL}$ \\
\hline
\end{tabular}

$\mathrm{PCR}=$ Polymerase chain reaction, $\mathrm{ASFV}=$ African swine fever virus

2011 IMB isolate, presenting with single and limited hemorrhages (Figure-1f, arrowed). There were common massive hemorrhages in the majority of lymph nodes in infection with Georgia 2007 (Figure-1g), while hemorrhages in lymph nodes developed only in few cases of Dilijan 2011 IMB infections (Figure-1h). Kidney studies showed that Georgia 2007 isolate caused multiple hemorrhages (Figure-1i), sometimes with the development of confluent hemorrhage, and Dilijan 2011 IMB isolate caused either single point hemorrhages (Figure-1j) or this pathology absent.

\section{Discussion}

In general, the atypical form of ASF (caused by Dilijan 2011 IMB isolate) described above demonstrates the characteristics of a subacute form of the disease, with the possibility to conversion to a chronic form. The new isolate developed an uncommon clinical manifestation of ASF - unlike the common subacute form, it demonstrated partially reduced the ability for hemadsorbtion and decreased frequency and intensity of hemorrhages. It also showed a less pronounced pathology of blood clotting system compared to the typical ASF induced by Georgia 2007 isolate [5]. Leukopenia which is common for disease produced by Georgia 2007 isolate is less pronounced and in the majority of cases presents in lymphopenia pattern.

Presumably, such phenomenon can be either a result of penetration of a new type of ASF virus with lower virulence into the zone of previous ASF outbreaks or variation in the same virus, with the arising of new, less virulent mutant strain.

It is known that the ASFV is capable of changing quickly enough to result in a transition from acute/ subacute disease to a chronic form. It is reported that the ASF virus is inclined to modification in the chronic form of the disease [6]. There can be several causes for the development of the chronic forms of 


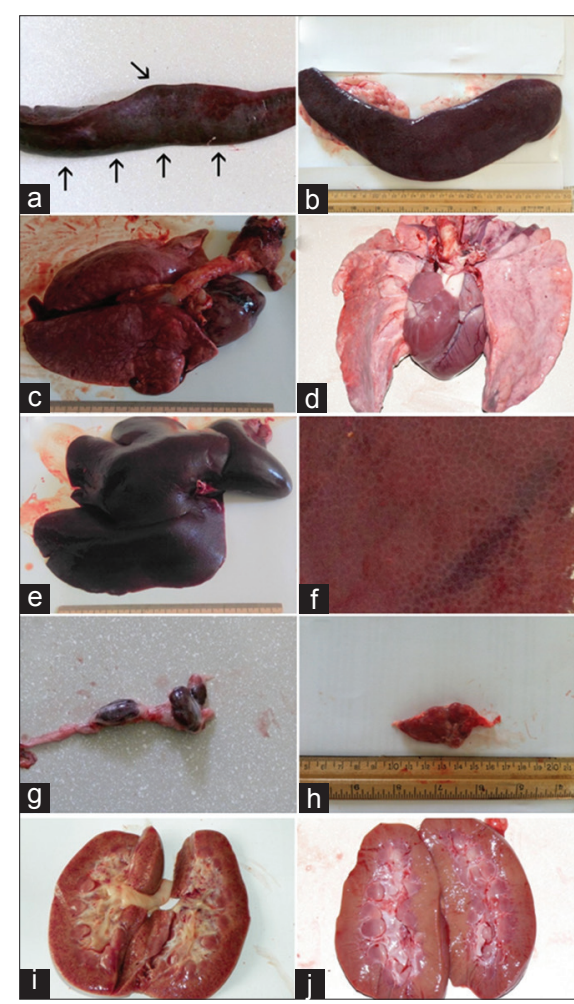

Figure-1: Comparative gross anatomical pathology. Left column - African swine fever virus (ASFV) Georgia 2007, right column - ASFV Dilijan 2011 Institute of Molecular Biology (IMB). (a) Spleen with hemorrhages (shown by arows) Georgia 2007. (b) Enlarged spleen without hemorrhages, infection by Dilijan 2011 IMB strain. (c) Heart and lungs with massive hemorrhages Georgia 2007. (d) Lungs with partial infarcts and point hemorrhages, infection by Dilijan 2011 IMB strain. (e) Liver with confluent hemorrhage, Georgia 2007. (f) Singe minor hemorrhages (shown by arows) Dilijan 2011 IMB. (g) Lymph nodes at 6 dpi infection by Georgia 2007 strain. (h) Lymph nodes at 10 dpi infection by Dilijan 2011 IMB strain. (i) Petechiated kidney at 6 dpi infection by Georgia 2007 strain. (j) Kidney almost without hemorrhages, at $10 \mathrm{dpi}$ infection by Dilijan 2011 IMB strain.

ASF. Primarily, chronic ASF can be associated with infection by moderate-to-low virulence isolates [6]. However, it should be noted that, during alltime observations of ASF in Armenia, all sequenced genomes belonged to the Georgia 2007. In Armenia, only ASF (II genotype) occurs, which has penetrated the country in 2007 demonstrating absolute mortality rate among sick animals at the initial stages. In the beginning, the only form of ASF in Armenia was the acute form [7]. However, in 2010-2011, there were cases of disease transition into a chronic form [2]. This effect can be dose-depended phenomena $[8,9]$. The possibility of dose-dependent disease courses has been discussed by Pietschmann et al. [10]. However, authors found no indication of prolonged or chronic individual courses on low-dose infection. Trade and movement of pigs and pork products appear to have been one of major factors in ASFV dissemination[11].

In Armenia, like in all Caucasus region, the majority of the swine production (over 90\%) can be classified as backyard and where very scarce information is available on pig trade patterns [12]. This type of swine production together with lack of information in combination with other factors such as the presence of wild boar populations and illegal trade of pigs and pig products contributed to the difficulties to ASF control [13]. Hence, we do not exclude the possibility of penetration in Armenia a new strain of genotype II, but the likelihood of such a scenario seems unlikely to us due to the closure of borders with Turkey and Azerbaijan, also because of the Muslim population of Iran, Azerbaijan, and Turkey who do not consume and therefore produce pork. This indicates that changes in the virulence of Armenian wild-type can be associated with some changes occurred in the genome of ASFV after introduction into Armenia. One of the important roles plays a change of main disease characteristics. The reasons of the persistence of ASFV in endemic areas, with small-scale but regular outbreaks in domestic pigs, is not well understood [14]. Unlike acute forms of ASF, chronic forms usually characterized by the absence of vascular lesions and by the presence of lesions in which bacteria are involved [15]. Moreover, as described by Arias and Sanchez-Vizcaino [16], the chronic form of the disease can spread the virus for long periods of time, which likely plays a key role in the persistence of the disease.

Most likely cause of uncommon ASF is the change in the virus genome, which is consistent with a typical evolution pattern of viruses. Although DNA viruses have a significantly lower rate of mutations, compared to RNA viruses, their variability is still much higher than that in cellular organisms. Emergences of new, less virulent mutant of ASF virus has high importance for the survival of the virus, as the chances of its transmission are being increased. It is well documented that DNA viruses have a tendency to establish prolonged, chronic, and inapparent (latent) persistent infections $[17,18]$. The changes in the clinical manifestations of unusual ASF which are described in our article support this view. In addition, chronically infected pigs can remain persistently infected which may contribute to the prolonged ability for virus transmission. Thus, they have an important significance in disease persistence in endemic areas [19-21]. The development of appropriate ASF control strategies would require intensive epidemiological studies that could favor in the understanding of viral evolution in natural conditions.

In the current study, we show for the first time formation of the unusual or transient form of ASF during the third epidemic wave in Armenia.

\section{Conclusion}

The new strain of ASF virus isolated from pigs in northeast Armenia caused distinct pathological changes (disease has turned into a more chronic infection during late autumn 2011), compared with acute form ASF (Georgia 2007). Nucleotide sequences 
obtained from the p72-based PCRs of Dilijan 2011 IMB virus clustered with $\mathrm{p} 72$ genotype II. So we can conclude arising of the unusual or transient form of ASF during the third epidemic wave in Armenia.

\section{Authors' Contributions}

ZAK and EMK designed the experiment. MAS, LHH, and HEV conducted the experiment. ZAK did technical writing and revision of the manuscript. ZAK and EMK prepared the manuscript. All authors have read and approved the final version of the manuscript.

\section{Acknowledgments}

The authors are thankful to the Directorate of the Institute of Molecular Biology of National Academy of Sciences for technical support. This research is self-sponsored.

\section{Competing Interests} interests.

The authors declare that they have no competing

\section{References}

1. Karalova, E., Zakaryan, H., Voskanyan, H., Arzumanyan, H., Hakobyan, A., Nersisyan, N., Saroyan, D., Karalyan, N., Tatoyan, M., Akopian, J., Gazaryantz, M., Mkrtchyan, Z., Pogosyan, L., Nersesova, L. and Karalyan, Z. (2015) Clinical and post-mortem investigations of genotype II induced African swine fever. Porc. Res., 5(1): 1-11.

2. Sargsyan, M.A., Karalyan, Z.A., Kotsinyan, A.R. and Voskanyan, H.E. (2016) Atypical African swine fever cases in Armenia. Agroscience, 697-698(9-10): 283-5.

3. Mur, L., Martínez-López, B. and Sánchez-Vizcaíno, J.M. (2012) Risk of African swine fever introduction into the European Union through transport-associated routes: Returning trucks and waste from international ships and planes. BMC Vet. Res., 8: 149.

4. Rodríguez, F., Fernández, A., Martín de las Mulas, J.P., Sierra, M.A. and Jover, A. (1996) African swine fever: Morphopathology of a viral haemorrhagic disease. Vet. Rec., 139(11): 249-254.

5. Zakaryan, H., Karalova, E., Voskanyan, H., Ter-Pogossyan, Z., Nersisyan, N., Hakobyan, A., Saroyan, D. and Karalyan, Z. (2014) Evaluation of hemostaseological status of pigs experimentally infected with African swine fever virus. Vet. Microbiol., 174(1-2): 223-228.

6. Costard, S., Mur, L., Lubroth, J., Sanchez-Vizcaino, J.M and Pfeiffer, D.U. (2013) Epidemiology of African swine fever virus. Virus Res., 173(1): 191-197.

7. Chapman, D.A., Darby, A.C., Da Silva, M., Upton, C., Radford, A.D. and Dixon, L.K. (2011) Genomic analysis of highly virulent Georgia 2007/1 isolate of African swine fever virus. Emerg. Infect. Dis. 17(4): 599-605.

8. Post, J., Weesendorp, E., Montoya, M. and Loeffen, W.L.
(2017) Influence of age and dose of African swine fever virus infections on clinical outcome and blood parameters in pigs. Viral. Immunol., 30(1): 58-69.

9. Sánchez-Cordón, P.J., Chapman, D., Jabbar, T., Reis, A.L., Goatley, L., Netherton, C.L., Taylor, G., Montoya, M. and Dixon, L. (2017) Different routes and doses influence protection in pigs immunised with the naturally attenuated African swine fever virus isolate OURT88/3. Antiviral Res., 138: $1-8$.

10. Pietschmann, J., Guinat, C., Beer, M., Pronin, V., Tauscher, K., Petrov, A., Keil, G. and Blome, S. (2015) Course and transmission characteristics of oral low-dose infection of domestic pigs and European wild boar with a Caucasian African swine fever virus isolate. Arch. Virol., 160(7): 1657-1667.

11. Simulundu, E., Lubaba, C.H., van Heerden, J., Kajihara, M., Mataa, L., Chambaro, H.M., Sinkala, Y., Munjita, S.M., Munang'andu, H.M., Nalubamba, K.S., Samui, K., Pandey, G.S., Takada, A. and Mweene, A.S. (2017) The epidemiology of African swine fever in "Nonendemic" regions of Zambia (1989-2015): Implications for disease prevention and control. Viruses, 9(9): pii: E236.

12. Kukielka, E.A., Martínez-López, B. and Beltrán-Alcrudo, D. (2017) Modeling the live-pig trade network in Georgia: Implications for disease prevention and control. PLoS One, 12(6): $\mathrm{e} 0178904$

13. Costard, S., Zagmutt, F.J., Porphyre, T. and Pfeiffer, D.U. (2015) Small-scale pig farmers' behavior, silent release of African swine fever virus and consequences for disease spread. Sci Rep., 5: 17074.

14. Abworo, E.O., Onzere, C., Oluoch, A.J., Riitho, V., Mwangi, W., Davies, J., Blome, S. and Peter, B.R. (2017) Detection of African swine fever virus in the tissues of asymptomatic pigs in smallholder farming systems along the Kenya-Uganda border: Implications for transmission in endemic areas and ASF surveillance in East Africa. J. Gen. Virol., 98(7): 1806-1814.

15. Moulton, J. and Coggins, L. (1968) Comparison of lesions in acute and chronic African swine fever. Cornell Vet., 58(3): 364-388.

16. Arias, M. and Sanchez-Vizcaino, J.M. (2002) African swine fever eradication: The Spanish model. In: Morilla, A., Jin, K., Zimmerman, J., editors. Trends in Emerging Viral Infections of Swine. Iowa State University Press, Ames. pp133-139.

17. Domingo, E., Webster, R.G. and Holland, J.J. (1999) Origin and Evolution of Viruses. Academic Press, New York.

18. Pan, I.C., Whyard, T.C., Hess, W.R., Yuasa, N. and Shimizu, M. (1998) Epitopic diversity of African swine fever virus. Virus Res., 9(2-3): 93-106.

19. Sánchez-Vizcaíno, J.M., Mur, L., Gomez-Villamandos, J.C. and Carrasco, L. (2015) An update on the epidemiology and pathology of African swine fever. J. Comp. Pathol., 152(1): 9-21.

20. Penrith, M.L., Vosloo, W. (2009) Review of African swine fever: Transmission spread and control. J S Afr Vet Assoc., 80(2): 58-62.

21. Gallardo, M.C., Reoyo, A.T., Fernández-Pinero, J., Iglesias, I., Muñoz, M.J. and Arias, M.L. African swine 